\title{
A Performance Comparison of Transfer Pricing and Tidy Cost Allocations in Presence of Product Market Competition and Congestion Costs
}

\author{
Robert F. Göx* \\ University of Magdeburg
}

First Draft, January 1999

\begin{abstract}
This paper compares the performance of transfer pricing and tidy cost allocations in a multiproduct firm in presence of output market competition and production externalities. In absence of competition, tidy cost allocations are creating inefficient allocations within the firm while transfer prices can always be adjusted to replicate the first best solution of the centralized firm. While the second result is well known, the first result draws a parallel to the impossibility of solving the free rider problem in team production by a profit sharing scheme. Under duopolistic competition, transfer prices are still the best accounting rule but the solution depends on the nature of competition on the final product market. When firms compete in prices, the strategic rationale requires to allocate more than the total cost of the congested service to the duopolistic departments. While transfer prices can still be adjusted accordingly, the tidyness requirement prevents the cost allocation scheme from providing the desired strategic incentives to the firms' managers. Under quantity competition, the strategic motive requires to allocate less than the cost of the service to the duopolistic departments. Although a tidy cost allocation scheme does not contradict the required direction of the strategic effect, the optimal allocation is at best found incidentally while the transfer prices can again always be adjusted in an optimal way.
\end{abstract}

\footnotetext{
${ }^{*}$ Dr. rer. pol. Robert F. Göx, Otto-von-Guericke-University of Magdeburg, Faculty of Economics and Management, PF 4120, 39016 Magdeburg. Tel.: +49/391/6718729, Fax: + 49/391/6711136, Email: goex@ww.uni-magdeburg.de
} 


\section{Introduction}

Divisionalized firms are often faced with situations in which multiple users are sharing common facilities or company wide services like a personnel department, a WATS line, a centralized maintenance department or a firm wide computer network. Since these jointly used resources are usually capacity constrained it is very likely that the firm's decentralized units will impose negative externalities on each other by excessive service demands. According to Zimmerman (1979) these externalities can take the form of delay costs, degradation of services or purchases of market substitutes for the centralized service that are not in the best interest of the firm. In his seminal 1979 paper ZIMMERMAN demonstrates that cost allocations can serve as a proxy for the difficult to measure opportunity costs of joint resource usage and lead the decentralized units to internalize the cost of the production externalities.

More recent work of GAL-OR (1993) and Hughes AND KAO (1998) suggests indicates that common service cost allocations can also provide strategic incentives for profit center managers faced with competition on the final product market. Both papers consider the impact of tidy cost allocations on the competitive behavior of two multiple product firms facing both duopolistic quantity competition and production externalities arising from the use of a centralized service ${ }^{1}$. Although the specific functional form of the congestion cost function assumed in both models makes it difficult to derive general results on the interaction between competitive effects and internal efficiency, it becomes evident from numerical computations performed by HUGHES AND KAO (1998) that decentralized firms are usually forcing their managers to behave as more aggressive competitors than centralized firms by employing a tidy cost allocation rule. The reason is that the tidyness requirement leads to an implicit subsidization of the firms' products as compared to the relevant costs under centralized decision making. As a result, both firms are usually earning strictly lower profits under decentralization except for some corner solutions where the whole congestion costs are allocated to one of the firms' profit centers. Despite its inefficiency decentralization is still a dominant strategy equilibrium in most cases because a centralized firm would be worse off when it would have to compete against a decentralized competitor. Thus, the firms are usually facing a prisoners' dilemma ${ }^{2}$.

A related strand of literature pursued by Alles And Datar (1998), NARAyanan AND Smith (1998), and Göx (1998) analyzes the use of transfer pricing as a commitment

\footnotetext{
${ }^{1}$ The major difference between both models is that the second division in GAL-OR (1993) operates on a perfectly competitive market while HUGHES AND KAO (1998) consider two duopolistic divisions acting on separate markets.

${ }^{2}$ See Hughes And Kao (1998), p. 277.
} 
device. In contrast to the above mentioned cost allocation literature, these papers mutually consider two divisionalized firms facing duopolistic price competition on the final product market in the absence of production externalities and find that the optimal transfer price should contain a markup over marginal cost to lead the firms' managers to raise their prices on the final product market to the mutual benefit of both firms. The intuition behind strategic transfer pricing is easily explained. Consider the Nash equilibrium in a price setting duopoly market. Both competitors would prefer to charge higher prices because any collusive strategy resulting in prices between the noncooperative equilibrium and the cartel solution increases both firms' profits. The problem is that cooperative agreements require either an enforceable contract or credible precommitments to be feasible. Since cartel contracts are illegal and tacit collusion usually provides incentives to cheat, ownermanaged firms are in general confined to the noncooperative equilibrium ${ }^{3}$

This reasoning also holds for vertically integrated firms in the case of centralized decision making. Consider the regular case of a divisionalized firm where the firm's headquarters delegates the pricing decision to a division manager and evaluates the agent's performance by his divisional profit. Since the transfer price is an exogenous parameter to the agent's profit maximization problem, headquarters can commit the agent to the desired high-price strategy by rising the transfer price above the intermediate product's marginal cost. Conversely, a centralized firm cannot credibly commit itself to the agents' strategy because the intermediate product's marginal cost are exogenous to its decision problem and hence, choosing the manager's equilibrium strategy would not be a profit maximizing strategy for the centralized firm. Thus, the strategic benefits of delegation imply a strict preference for decentralization over centralization ${ }^{4}$.

Given the diversity of these results this paper integrates and extends the existing literature by examining the possible strategic benefits of both transfer pricing and tidy cost allocations in presence of negative production externalities within the firm. The purpose of this extension is twofold. First, the paper attempts to disentangle the impact of cost allocations on the internal efficiency of the firm from strategic considerations. To perform this task the first step of the analysis contains a model of two multiple product

\footnotetext{
${ }^{3}$ See Jaquemin And Slade (1988), p. 417. In a multiperiod setting, firms may carry out irreversible investments to create credible precomittments see e.g. BRANDER AND SpENCER (1983). But these may be to costly to carry out and hence incredible see Tirole (1988), chapter 8, for a review of related models.

${ }^{4}$ The basic idea behind the strategic use of both transfer prices and cost allocations is closely related to a branch of the industrial organizations literature pursued by Vickers (1985), Fershtman And JudD (1987) and Sklivas (1987). Based on the pioneering work of Schelling (1960), these authors demonstrate the strategic benefits of incentive contracts as credible precommitments vis-a-vis a competitor when managers are allowed to play the market game on behalf of the owners.
} 
monopolies facing congestion costs. The solution of this model serves as a benchmark case for the second part of the paper, where two competing multiple product firms are considered which can either compete in prices or quantities. Accordingly the second aim of the paper is to identify the optimal method of allocating the costs of the congested service for a given form of competition on the final product market.

The remainder of the analysis is organized as follows. The next section explains the basic assumptions about the firms' cost and demand structure. The third section compares the use of transfer pricing versus cost allocations in the benchmark setting and the fourth section extends the setting to the duopoly case under price and quantity competition. Section five concludes this paper with a summary and discussion of the main results.

\section{Structure of cost and demand}

Consider two vertically integrated multiproduct firms $(i=1,2)$, each of them consisting of headquarters (HQ), a centralized service department $(k=0)$, and two marketing divisions $(k=1,2)$. To keep the results of the analysis comparable with the previous literature on strategic cost allocations it will be assumed that the marketing departments are imposing negative externalities on each other by utilizing the centralized service and that the cost of the congested service can be captured by the following multiplicative cost function

$$
C_{i 0}=\delta q_{i 1} q_{i 2},
$$

where $\delta>0$ is an industry wide scale parameter and $q_{i k}$ denotes the output quantity of firm $i$ 's marketing department $k^{5}$. The multiplicative form of the common service cost function obviously implies that the marginal cost of service usage by department $k$ is increasing with the service demand of department $l, l \neq k \in\{1,2\}$. Assume for simplicity that there are no other production costs apart from the costs of the congested service, then the service demand of division $k$ will depend on the type of cost reimbursement employed by the firms' headquarters which will in turn be determined by the nature of competition on the final product market. Two competitive scenarios will be considered: The monopoly case and the duopoly case. When one of the firm's marketing divisions possesses monopoly power on its output market its revenue is given by the following function

$$
R_{i k}\left(q_{i k}\right)=p_{i k}\left(q_{i k}\right) q_{i k}
$$

which is assumed to be twice differentiable and strictly concave in its argument $q_{i k}$. In the duopoly case both marketing divisions $k$ of firm 1 and 2 are assumed to serve the

\footnotetext{
${ }^{5}$ Like in GaL-Or (1993) and Hughes AND KAO (1998) a fixed component might be added to the cost function to account for the sunk capacity costs of the service. However, this modification would obviously have no qualitative impact on the model results and is thus left out for the sake of simplicity.
} 
same market each of them offering a different brand within a larger product class. The firms can, however, either compete in prices $\left(p_{i k}\right)$ or quantities $\left(q_{i k}\right)$. In the former case the demand for the product of firm $i$ is given by $D_{i k}:=q_{i k}\left(p_{i k}, p_{j k}\right)$ whereas in the latter case the firms will consider the inverse demand function $D_{i k}^{-1}:=p_{i k}\left(q_{i k}, q_{j k}\right)$ in their profit maximization problems. The demand system is assumed to satisfy the usual properties in partial equilibrium analysis:

$$
\frac{\partial q_{i k}}{\partial p_{i k}}<0, \frac{\partial q_{i k}}{\partial p_{j k}}>0, \frac{\partial p_{i k}}{\partial q_{i k}}<0, \frac{\partial p_{i k}}{\partial q_{j k}}<0
$$

While the first and the third assumption in (3) are reflecting the negative relationship between a product's demand and its own price as predicted by consumer theory, the second and the fourth condition in (3) are exhibiting the fact that the firms' products are substitutes from the consumers' point of view. Suppose further that the cross effects are smaller than the direct effects: ${ }^{6}$

$$
\frac{\partial q_{i k}}{\partial p_{j k}}=\frac{\partial q_{j k}}{\partial p_{i k}}<\left|\frac{\partial q_{i k}}{\partial p_{i k}}\right|, \quad \frac{\partial p_{i k}}{\partial q_{i k}}<\frac{\partial p_{i k}}{\partial q_{j k}}=\frac{\partial p_{j k}}{\partial q_{i k}}
$$

The symmetry assumption merely simplifies the analysis and says that a change in firm $i$ 's price (quantity) has the same effect on firm $j$ 's demand quantity (price) as a change in $j$ 's price (quantity) on $i$ 's demand quantity (price). The fact that the direct effects are larger than the cross effects on demand states that both firms' products are not perfectly substitutable and rules out the well known Bertrand paradox for the case of price competition ${ }^{7}$.

\section{Benchmark case: multiproduct monopoly}

\subsection{Centralized decision making}

Consider first the decision problem of the centralized firms when both marketing divisions act as monopolists on their final product markets. Given the above assumptions about the firms' cost and demand conditions the centralized firm's profit can be computed as

\footnotetext{
${ }^{6}$ It is easy to verify that a linear demand system satisfies conditions (3) and (4). However, even in the simplest case of quantity competition with identical products it is difficult to obtain interpretable closed form solutions for the optimale cost shares in the tidy cost allocation case, see e.g. HuGHES AND KAO (1998). Thus, the major advantage of a more general demand function approach is to keep the results clear rather than covering a broader range of possible demand situations.

${ }^{7}$ The Bertrand paradox occures in the case of identical products and forces the firms to set their prices equal to marginal cost to prevent the competitor from capturing the entire market by marginally undercutting the rivals price, see e.g. TIROLE (1988).
} 
the sum of the marketing department's revenues minus the service department's costs:

$$
\Pi_{i}=R_{i 1}\left(q_{i 1}\right)+R_{i 2}\left(q_{i 2}\right)-\delta q_{i 1} q_{i 2} \quad i \in\{1,2\}
$$

Since both firms are facing the identical decision problem of maximizing $\Pi_{i}$ with respect to $q_{i 1}$ and $q_{i 2}$ respectively the firm index $i$ will be suppressed in this section. Accordingly the first order conditions of the centralized multiproduct monopolists are given by the following expression

$$
\frac{\partial \Pi}{\partial q_{k}}=\frac{\partial R_{k}}{\partial q_{k}}-\delta q_{l}=0 \quad k, l \in\{1,2\}, k \neq l
$$

According to (6) the centralized firm internalizes the externality completely by equalizing each products marginal revenue with its marginal congestion cost. The optimal quantities are easily obtained by solving the system defined by (6) for $q_{1}$ and $q_{2}$. The purpose of the next two subsections is to examine if this benchmark solution can be replicated in a decentralized firm where the authority over the optimal production quantities is delegated to the divisional managers and the coordination device in place is either transfer pricing or a tidy cost allocation rule. As noted in the introduction, this part of the analysis is aimed to disentangle the problem of achieving internal efficiency from strategic considerations although there is no model endogenous gain from decentralization in the monopoly setting. Such gains could, however, arise form informational asymmetries between HQ and the divisions which are beyond the scope of this paper but have been extensively discussed in the transfer pricing literature ${ }^{8}$.

\subsection{Transfer pricing}

Consider first the problem of finding a transfer price that leads the autonomous profit center managers to internalize the congestion costs in order to maximize the profits of the whole firm ${ }^{9}$. The optimization procedure consists of two stages. On stage one HQ sets the transfer price, and on stage two the divisional managers decide on their optimal output quantities. The solution of this two stage optimization problem is obtained by backward induction starting with the managers's profit maximization problem on stage two:

$$
\max _{q_{k}} \Pi_{k}=R_{k}\left(q_{k}\right)-t_{k} q_{k}, \quad k \in\{1,2\},
$$

where $t_{k}$ denotes the per unit transfer price that division $k$ is charged for utilizing the centralized service. Obviously, divison $k$ will determine its optimal output quantity by

\footnotetext{
${ }^{8}$ Examples of transfer pricing papers dealing with various aspects of assymetric information are AMERShi And Cheng (1988), Banker and Datar (1992), Christensen and Demski (1990), Edlin and Reichelstein (1995), Ronen and Balachandran (1988), Vaysman (1996), and Wagenhofer (1994).

${ }^{9}$ The classical reference for problems of this type is HiRShLEIFER (1956).
} 
setting marginal revenue equal to the transfer price for the congested service:

$$
\frac{\partial R_{k}}{\partial q_{k}}-t_{k}=0
$$

Since HQ possesses all relevant information about divisional profits, it will anticipate the managers' optimal decisions and regard the optimal quantities as functions of the transfer price in its first stage optimization problem, thus

$$
q_{k}^{*}\left(t_{k}\right)=\underset{q_{k}}{\arg \max } \Pi_{k}\left(q_{k}, t_{k}\right), \quad k \in\{1,2\}
$$

from HQ's point of view. Accordingly HQ maximizes the sum of divisional profits

$$
\Pi\left(t_{1}, t_{2}\right)=V_{1}\left(t_{1}\right)+V_{2}\left(t_{2}\right)+t_{1} q_{1}^{*}\left(t_{1}\right)+t_{2} q_{2}^{*}\left(t_{2}\right)-\delta q_{1}^{*}\left(t_{1}\right) q_{2}^{*}\left(t_{2}\right)
$$

with respect to $t_{1}$ and $t_{2}$, where $V_{k}\left(t_{k}\right):=\Pi_{k}\left(q_{k}^{*}\left(t_{k}\right), t_{k}\right)$ denotes division $k$ 's maximum profit for a given transfer price $t_{k}$. Since the derivatives of the divisions' maximum value functions are given by $d V_{k}\left(t_{k}\right) / d t_{k}=\partial \Pi_{k}\left(t_{k}\right) / \partial t_{k}=-q_{k}^{*}\left(t_{k}\right)$ from Hotelling's Lemma, the firms' optimization problem yields the following solutions

$$
t_{k}^{*}=\delta q_{l}^{*}\left(t_{l}^{*}\right), \quad k, l \in\{1,2\}, k \neq l .
$$

According to (10) HQ charges each division exactly the marginal cost of the congested service. Moreover, a comparison with the optimal policy of the centralized firm yields the following result:

Lemma 1 The decision problem of the centralized firm can efficiently be delegated to the divisional level by transfer pricing.

Proof Substituting the optimal transfer price from equation (10) into the managers' first order conditions (8) yields the optimality condition of the centralized firm given by (6)

Lemma 1 confirms the well known result of HirshleIfER (1956) for the case of a multiproduct firm under technological dependence among the firm's divisions ${ }^{10}$. Although this result is not surprising given the underlying model assumptions it will be important to note for the following analysis that a decentralized firm can always achieve the same profit level as a centralized firm by employing a transfer pricing scheme.

\subsection{Tidy Cost Allocation}

The purpose of this subsection is to explore if a firm can still efficiently decompose its optimization problem into two separate decision problems solved at the divisional level by

\footnotetext{
${ }^{10}$ It should be mentioned that HIRSHLEIFER already provides a short discussion of this case but not a solution.
} 
employing a tidy cost allocation rule instead of transfer pricing. The tidyness requirement says that the cost allocation scheme must allocate exactly the total cost of the service department to its users (DEMSKI, 1981). Since there are only two users, the cost allocation scheme can be defined by a single parameter $\alpha, \alpha \in[0,1]$ denoting the cost share of division 1. Thus, the share of division 2 can be computed as $1-\alpha$, and the divisional profits are given by the following expressions

$$
\begin{aligned}
& \Pi_{1}=R_{1}\left(q_{1}\right)-\alpha \delta q_{1} q_{2}, \\
& \Pi_{2}=R_{2}\left(q_{2}\right)-(1-\alpha) \delta q_{1} q_{2} .
\end{aligned}
$$

It is obvious from the profit expressions (11) and (12) that the divisions' profits are functions of both departments' output quantities, whereas in the last section the output quantity of division $k$ had no direct impact on the $l$ 's profit for given transfer prices $t_{k}$ and $t_{l}$. Thus, the second stage profit maximization problems are no longer simple decision problems like in the transfer pricing case, rather the optimal quantities are determined as the equilibrium outcome of a non-cooperative game between both marketing managers. In determining the optimal cost shares on the first stage of the game HQ must consider the equilibrium strategies of the second stage subgame. The conditions for a NASH-Equilibrium in the managers's subgame are obtained by maximizing divisional profits with respect to $q_{1}$ and $q_{2}$ :

$$
\begin{aligned}
& \frac{\partial \Pi_{1}}{\partial q_{1}}=\frac{d R_{1}\left(q_{1}\right)}{d q_{1}}-\alpha \delta q_{2}=0 \\
& \frac{\partial \Pi_{2}}{\partial q_{2}}=\frac{d R_{2}\left(q_{2}\right)}{d q_{2}}-(1-\alpha) \delta q_{1}=0
\end{aligned}
$$

where the equilibrium quantities are obtained by solving the equation system defined by (13) and (14) for $q_{1}$ and $q_{2}$. Applying the solution procedure proposed in the last subsection, it will be supposed that HQ anticipates the managers' equilibrium strategies and regards the optimal quantities as functions of the cost share parameter $\alpha$ :

$$
q_{k}^{*}(\alpha)=\underset{q_{k}}{\arg \max } \Pi_{k}\left(q_{k}, q_{j}^{*}, \alpha\right), \quad k, l \in\{1,2\}, k \neq l .
$$

In accordance with the previous section it will be helpful to introduce the following notation for the equilibrium profit of division $k$ :

$$
\Pi_{k}\left(q_{k}^{*}(\alpha), q_{l}^{*}(\alpha), \alpha\right):=V_{k}(\alpha), \quad k, l \in\{1,2\}, k \neq l .
$$

The first stage maximization problem of HQ is then given by

$$
\max _{\alpha} \Pi(\alpha)=V_{1}(\alpha)+V_{2}(\alpha)
$$

The profit expression (16) indicates that not only the equilibrium outputs but also the firm's profit is a sole function of the cost allocation parameter $\alpha$ from HQ's point of view. 
Thus, HQ faces the simple decision problem of choosing the optimal cost share. In game theoretic terms this task is equivalent to selecting the optimal subgame from the set of subgames defined by the set of admissible values $\alpha \in[0,1]$. The necessary condition for the optimal solution of the firm's cost allocation problem is given by ${ }^{11}$

$$
\frac{\partial \Pi(\alpha)}{\partial \alpha}=\frac{\partial \Pi_{1}}{\partial q_{2}} \frac{d q_{2}^{*}}{d \alpha}+\frac{\partial \Pi_{2}}{\partial q_{1}} \frac{d q_{1}^{*}}{d \alpha}=0 .
$$

According to (17) HQ seeks to solve the allocation problem by equalizing the marginal congestion costs that the departments are imposing on each other. Hence, in equilibrium the managers will be forced to select output quantities such that each department bears the same marginal cost burden caused by the production externality. Substituting the expressions

$$
\frac{\partial \Pi_{1}}{\partial q_{2}}=-\alpha \delta q_{1}, \text { and } \frac{\partial \Pi_{2}}{\partial q_{1}}=-(1-\alpha) \delta q_{2}
$$

for the cross effects on divisional profits into (17) and solving for $\alpha$ yields the optimal cost share of division 1 :

$$
\alpha^{*}=\frac{q_{2}^{*}(\alpha) \frac{d q_{1}^{*}}{d \alpha}}{q_{2}^{*}(\alpha) \frac{d q_{1}^{*}}{d \alpha}-q_{1}^{*}(\alpha) \frac{d q_{2}^{*}}{d \alpha}} .
$$

The following Lemma allows to investigate the structure of the optimal solution

Lemma 2 The equilibrium output of division 1 is increasing and the equilibrium output of division 2 is decreasing in division 1 's cost share:

$$
\frac{d q_{1}^{*}}{d \alpha}<0 \quad \text { and } \quad \frac{d q_{2}^{*}}{d \alpha}>0
$$

\section{Proof see appendix.}

Since the equilibrium quantities cannot be negative, both the numerator and the denominator of (19) are strictly negative for interior solutions of the managers' subgame from Lemma 2. Moreover, since the denominator is larger than the numerator, the optimal cost shares will assume values form the interval $(0,1)$ for positive equilibrium quantities. However, the following proposition states that the resulting allocation will be inefficient.

Proposition 1 There exists no tidy cost allocation scheme that leads the divison managers to internalize the full cost of the production externalities in their profit maximization problems.

\footnotetext{
${ }^{11}$ See appendix for a detailed derivation of this expression.
} 
Proof Substituting the optimal cost share parameter $\alpha^{*} \in(0,1)$ into the division managers first order conditions (13) and (14), and replacing marginal revenues by marginal cost from HQ's first order condition (6) yields

$$
\alpha^{*}=1 \quad \text { and } \quad \alpha^{*}=0,
$$

a contradiction

The positive result about transfer pricing in Lemma 1 is contrasted by the negative result about cost allocations in Proposition 1. Unless one of the marketing divisions produces zero output in equilibrium under the optimal cost allocation scheme, the firm should strictly prefer centralization over decentralization. It is a straightforward task to demonstrate that the loss associated with the cost allocation scheme is solely caused by the tidyness requirement. Comparing the first order conditions of the centralized firm with the managers equilibrium conditions yields immediately that the firm can implement the optimal allocation by charging each division the entire cost of the service department. As a result the firm would, however, allocate twice of the service departments costs to the marketing divisions. This is exactly the solution under the transfer pricing scheme: Under transfer pricing the costs of department $k$ are given by $C_{k}=t_{k} q_{k}$; substituting the optimal transfer price from (10) yields

$$
C_{k}=\delta q_{1}^{*}\left(t_{1}^{*}\right) q_{2}^{*}\left(t_{2}^{*}\right)=C_{0}(\cdot), \quad k=1,2 .
$$

Strictly speaking the tidyness requirement acts like imposing a budget balance constraint

$$
t_{1} q_{1}+t_{2} q_{2}=C_{0}
$$

on the firm's transfer pricing problem and prevents it from achieving the first best solution in the decentralized setting. The problem of achieving efficiency in decentralized decision making under a tidy cost allocation rule is very similar to the attempt of solving the free rider problem in team production by a profit sharing scheme. According to Alchian AND Demsetz (1972), and Holmström (1982) it is impossible to exploit the benefits from complementary inputs (i.e. positive externalities) within a production team without introducing a residual claimant whose "primary role is to break the budget balance constraint"12. This is exactly the role of HQ in the transfer pricing setting. However, even if the tidyness requirement would be relaxed, transfer pricing would still be preferable from a more practical point of view. Since the division managers must only solve a simple decision problem under transfer pricing whereas they must also anticipate the other manager's production decision in the cost allocation case, the maximization problem is less complex in the former environment than in the latter one.

\footnotetext{
${ }^{12}$ Holmström (1982), p. 325.
} 


\section{Duopoly}

\subsection{Centralized decision making}

To analyze the impact of competition on the firms' allocation problem we will suppose from now on that division 1 faces duopolistic competition on its final product market while division 2 still possesses monopoly power. Consider first the maximization problem of the competing centralized firms. Obviously, the firms' profits will depend on the nature of competition. Let $\mathbf{a}=\left(a_{i 1}, a_{j 1}\right)$ denote the vector of the firms' decision variables, then $\mathbf{a}=\mathbf{q}=\left(q_{i 1}, q_{j 1}\right)$ when the firms compete in quantities and $\mathbf{a}=\mathbf{p}=\left(p_{i 1}, p_{j 1}\right)$ when the firms compete in prices. Substituting the demand functions defined in section 2 yields the following profit expression for firm $i$ :

$$
\Pi_{i}\left(a_{i 1}, a_{j 1}, q_{i 2}\right)= \begin{cases}p_{i 1}\left(q_{i 1}, q_{j 1}\right) q_{i 1}+R_{i 2}\left(q_{i 2}\right)-\delta q_{i 1} q_{i 2} & \text { for } \mathbf{a}=\mathbf{q} \\ p_{i 1} q_{i 1}\left(p_{i 1}, p_{j 1}\right)+R_{i 2}\left(q_{i 2}\right)-\delta q_{i 1}\left(p_{i 1}, p_{j 1}\right) q_{i 2} & \text { for } \mathbf{a}=\mathbf{p} .\end{cases}
$$

Throughout it will be assumed that the profit function is strictly concave and twice continuously differentiable in both decision variables $a_{i 1}$ and $q_{i 2}$ respectively. While the first order condition for product 2 ,

$$
\frac{\partial \Pi_{i}}{\partial q_{i 2}}=\frac{d R_{i 2}}{d q_{i 2}}-\delta q_{i 1}, \quad i \in\{1,2\},
$$

remains unchanged as compared to the multiproduct monopoly case (except for the firm index $i$ ), the conditions for a NAsH-equilibrium on the duopoly market become:

$$
\frac{\partial \Pi_{i}}{\partial a_{i 1}}=\left\{\begin{array}{c}
\frac{\partial p_{i 1}}{\partial q_{i 1}} q_{i 1}+p_{i 1}\left(q_{i 1}, q_{j 1}\right)-\delta q_{i 2}=0 \text { for } \mathbf{a}=\mathbf{q} \\
q_{i 1}\left(p_{i 1}, p_{j 1}\right)+\left(p_{i 1}-\delta q_{i 2}\right) \frac{\partial q_{i 1}}{\partial p_{i 1}}=0 \text { for } \mathbf{a}=\mathbf{p} .
\end{array}\right.
$$

The system of first order conditions given by (23) implicitly defines the firms' reaction functions. Closed form solutions, specifying the best response $a_{i 1}^{*}\left(a_{j 1}\right)$ of firm $i$ to a given strategy of firm $j$, are obtained by solving the first order condition of firm $i$ for $a_{i 1}$. Given the assumptions about the demand system, the reaction function of firm $i$ will have a negative slope under quantity competition and a positive slope under price competition. Thus, the higher the price (quantity) of firm $j$, the higher the optimal price (the lower the optimal quantity) of firm $i$. This is due to the fact that quantities are strategic substitutes while prices are strategic complements ${ }^{13}$. A more formal statement of this relationship is given by the following condition

$$
\frac{\partial^{2} \Pi_{i}}{\partial q_{i 1} \partial q_{j 1}}<0 \text { and } \quad \frac{\partial^{2} \Pi_{i}}{\partial p_{i 1} \partial p_{j 1}}>0
$$

\footnotetext{
${ }^{13}$ See Bulow, Geanakoplos And Klemperer (1985).
} 
i.e. the marginal profit of firm $i$ increases with firm $j$ 's price and decreases with firm $j$ 's quantity. Nevertheless, a closer inspection of (23) indicates that the centralized firm treats the marginal congestion costs of division $2\left(-\delta q_{i 2}\right)$ just as the multiproduct monopolist does in his first order condition (6). The nature of competition has therefore no qualitative impact on the relevant costs for the decision of the centralized firm. However, the optimal policy must not only consider internal efficiency but also the competitor's output market strategy ${ }^{14}$. To provide the necessary conditions for the existence of a unique NAsHequilibrium in the duopoly game, assume that the firms first solve (22) for $q_{i 2}$ and then substitute the resulting solution $q_{i 2}^{*}\left(q_{i 1}\right)$ into $(23)$. The NASH-equilibrium $\mathbf{a}^{*}=\left(a_{11}^{*}, a_{21}^{*}\right)$ will be unique when the following condition holds ${ }^{15}$ :

$$
\frac{\partial^{2} \Pi_{i}}{\partial a_{i 1}^{2}} \frac{\partial^{2} \Pi_{j}}{\partial a_{j 1}^{2}}-\frac{\partial^{2} \Pi_{i}}{\partial a_{i 1} \partial a_{j 1}} \frac{\partial^{2} \Pi_{j}}{\partial a_{j 1} \partial a_{i 1}}>0,
$$

where the profit of firm $i$ is given by $\Pi_{i}\left(a_{i 1}, a_{j 1}\right):=\Pi_{i}\left(p_{i 1}, p_{j 1}, q_{i 2}^{*}\left(q_{i 1}\left(p_{i 1}, p_{j 1}\right)\right)\right)$ when firms compete in prices and $\Pi_{i}\left(a_{i 1}, a_{j 1}\right):=\Pi_{i}\left(q_{i 1}, q_{j 1}, q_{i 2}^{*}\left(q_{i 1}\right)\right)$ when firms compete in quantities respectively.

\subsection{Strategic Transfer Pricing}

In the decentralized setting the well known two stage optimization procedure applies. On stage one the firms' HQ's determine their transfer prices for both departments. Whereas on stage two the marketing managers observe the outcome of the first stage game before they decide on their equilibrium strategies ${ }^{16}$. However, unlike the multiproduct monopoly case the first stage transfer pricing decisions are obtained as equilibrium strategies of a non-cooperative game between both firms' HQ's. Working backwards we first consider the managers' decision problems on stage two:

$$
\begin{aligned}
\max _{a_{i 1}} \Pi_{i 1}\left(a_{i 1}, a_{j 1}\right) & = \begin{cases}p_{i 1}\left(q_{i 1}, q_{j 1}\right) q_{i 1}-t_{i 1} q_{i 1} & \text { for } \mathbf{a}=\mathbf{q} \\
p_{i 1} q_{i 1}\left(p_{i 1}, p_{j 1}\right)-t_{i 1} q_{i 1}\left(p_{i 1}, p_{j 1}\right) & \text { for } \mathbf{a}=\mathbf{p}\end{cases} \\
\text { and } \max _{q_{i 2}} \Pi_{i 2}\left(q_{i 2}\right) & =R_{i 2}\left(q_{i 2}\right)-t_{i 2} q_{i 2},
\end{aligned}
$$

where $t_{i k}$ designates the transfer price that HQ $i$ charges its division $k$ for each unit of the congested service. Starting with the market game between the competing divisions 1

\footnotetext{
${ }^{14}$ In particular the equilibrium strategies must, in general, be computed as the solution of the equation system defined by (22) and (23) for $i=1,2 ; i \neq j$.

${ }^{15}$ See e.g. Dixit (1986), p.109.

${ }^{16}$ The assumption that the managers observe their competitors' transfer prices is crucial for the existence of a strategic transfer pricing equilibrium. See Göx (1998) for a formal proof of this requirement and section five for a discussion of this assumption.
} 
of both firms, we first determine the necessary conditions for a Nash-equilibrium. These are given by:

$$
\frac{\partial \Pi_{i 1}}{\partial a_{i 1}}=\left\{\begin{array}{c}
\frac{\partial p_{i 1}}{\partial q_{i 1}} q_{i 1}+p_{i 1}\left(q_{i 1}, q_{j 1}\right)-t_{i 1}=0 \text { for } \mathbf{a}=\mathbf{q} \\
q_{i 1}\left(p_{i 1}, p_{j 1}\right)+\left(p_{i 1}-t_{i 1}\right) \frac{\partial q_{i 1}}{\partial p_{i 1}}=0 \text { for } \mathbf{a}=\mathbf{p}
\end{array}\right.
$$

From (28) the managers' second stage equilibrium prices or quantities respectively are functions of both firms' transfer prices $t_{11}$ and $t_{21}$ from the perspective of their HQ's. Thus, the equilibrium strategy of manager $i 1$ can be written as

$$
a_{i 1}^{*}\left(t_{i 1}, t_{j 1}\right)=\underset{a_{i 1}}{\arg \max } \Pi_{i 1}\left(a_{i 1}, a_{j 1}^{*}, t_{i 1}\right), \quad i, j \in\{1,2\}, i \neq j,
$$

yielding the following equilibrium profit for divison 1 of firm $i$

$$
V_{i 1}\left(t_{i 1}, t_{j 1}\right):=\Pi_{i 1}\left(a_{i 1}^{*}\left(t_{i 1}, t_{j 1}\right), a_{1 j}^{*}\left(t_{i 1}, t_{j 1}\right), t_{i 1}\right), \quad i, j \in\{1,2\}, i \neq j .
$$

It remains to specify the stage two decision of division 2. Since the quantity decision of the monopolist divison is independent of division 1's equilibrium strategy for given transfer prices $t_{i 1}$ and $t_{i 2}$ from (27), both the optimal output quantity $q_{i 2}^{*}\left(t_{i 2}\right)$ and the maximum profit $V_{i 2}\left(t_{i 2}\right):=\Pi_{i 2}\left(q_{i 2}^{*}\left(t_{i 2}\right), t_{i 2}\right)$ of division 2 can be defined as a function of its own transfer price $t_{i 2}$ like in section 3.2. Accordingly, the first stage decision problem of HQ $i$ can be expressed as

$$
\begin{aligned}
\max _{t_{i 1}, t_{i 2}} \quad \Pi_{i}= & V_{i 1}\left(t_{i 1}, t_{j 1}\right)+V_{i 2}\left(t_{i 2}\right)+t_{i 1} q_{i 1}^{*}\left(t_{i 1}, t_{j 1}\right)+t_{i 2} q_{i 2}^{*}\left(t_{i 2}\right) \\
& -\delta q_{i 1}^{*}\left(t_{i 1}, t_{j 1}\right) q_{i 2}^{*}\left(t_{i 2}\right), \quad i, j \in\{1,2\}, i \neq j,
\end{aligned}
$$

where $q_{i 1}^{*}\left(t_{i 1}, t_{j 1}\right)$ denotes the equilibrium output of division $i 1$ under quantity competition and the equilibrium demand $q_{i 1}^{*}\left(t_{i 1}, t_{j 1}\right):=q_{i 1}\left(p_{i 1}^{*}\left(t_{i 1}, t_{j 1}\right), p_{j 1}^{*}\left(t_{i 1}, t_{j 1}\right)\right)$ under price competition. Omitting the arguments in (31) allows to derive the following general expression for HQ $i$ 's first order conditions

$$
\frac{\partial \Pi_{i}}{\partial t_{i k}}=\frac{\partial V_{i k}(\cdot)}{\partial t_{i k}}+q_{i k}^{*}(\cdot)+\left(t_{i k}-\delta q_{i l}^{*}(\cdot)\right) \frac{\partial q_{i k}^{*}}{\partial t_{i k}} \quad i \in\{1,2\}, k \in\{1,2\}, k \neq l .
$$

Since in the monopoly case $d V_{i 2} / d t_{i 2}=-q_{i 2}^{*}\left(t_{i 2}\right)$ form the envelope theorem, the first two terms in (32) cancel out in case of division 2 and the optimal transfer price $t_{i 2}^{*}$ can immediately be identified as

$$
t_{i 2}^{*}=\delta q_{i 1}^{*}\left(t_{i 1}^{*}, t_{j 1}^{*}\right), \quad i, j \in\{1,2\}, i \neq j .
$$

For a given pair of equilibrium transfer prices $\left(t_{i 1}^{*}, t_{j 1}^{*}\right)$ the monopolistic departments of both firms are charged the marginal cost of the congested service like in the multiproduct monopoly setting of section 3.2. Plugging the optimal transfer price $t_{i 2}^{*}$ into the manager's 
profit function (27) and differentiating with respect to $q_{i 2}$ yields the well known first order condition of the centralized firm given by (22). Nevertheless, since $t_{i 2}^{*}$ depends on the equilibrium quantity $q_{i 1}^{*}\left(t_{i 1}^{*}, t_{j 1}^{*}\right)$ the optimal output quantities of department 2 will be different in both settings, if the optimal transfer prices $t_{11}^{*}$ and $t_{21}^{*}$ deviate from the marginal costs of the congested service. To determine the transfer pricing equilibrium we first differentiate the reduced profit function (30) of division 2 with respect $t_{i 1}$ :

$$
\begin{aligned}
\frac{\partial V_{i 1}}{\partial t_{i 1}} & =\frac{\partial \Pi_{i 1}}{\partial a_{i 1}} \frac{\partial a_{i 1}^{*}}{\partial t_{i 1}}+\frac{\partial \Pi_{i 1}}{\partial a_{j 1}} \frac{\partial a_{j 1}^{*}}{\partial t_{i 1}}+\frac{\partial \Pi_{i 1}}{\partial t_{i 1}} \\
& =0+\Delta_{i}\left(a_{j 1}\right)-q_{i 1}^{*}\left(t_{i 1}, t_{j 1}\right), \quad i, j \in\{1,2\}, i \neq j,
\end{aligned}
$$

where the first term must be zero from the manager's equilibrium condition and the third term represents the cost effect resulting form a marginal increase of the transfer price. The distinguishing term from the monopoly case is, however, the second term

$$
\Delta_{i}\left(a_{j 1}\right):=\frac{\partial \Pi_{i 1}}{\partial a_{j 1}} \frac{\partial a_{j 1}^{*}}{\partial t_{i 1}}
$$

This term captures the profit impact of firm $j$ 's reaction to a marginal increase in firm $i$ 's transfer price. For a better understanding of this effect consider first the case of price competition. When HQ $i$ raises its transfer price, the manager of department $i 1$ will face an increasing marginal cost curve and optimally respond by charging a higher final product market price. Although his profit does not directly depend on $t_{i 1}$, the competitor will obviously react to this price change because his profit depends on $p_{i 1}$. Moreover, since prices are strategic complements the best response of manager $j 1$ is to increase his price as well. A similar observation can be made for the case of quantity competition. When firm $i$ raises its transfer price, manager $i 1$ will reduce his output quantity. However, since quantities are strategic substitutes the competitor's best response will be a reduction of his output. The preceding considerations can be summarized as follows:

Lemma 3 A marginal shift of firm i's transfer prices causes the following equilibrium reactions in the manager's market game on stage two

$$
\frac{\partial p_{i 1}^{*}}{\partial t_{i 1}}>0, \quad \frac{\partial p_{j 1}^{*}}{\partial t_{i 1}}>0, \quad \frac{\partial q_{i 1}^{*}}{\partial t_{i 1}}<0, \quad \frac{\partial q_{j 1}^{*}}{\partial t_{i 1}}>0
$$

Proof see appendix.

Thus, both firms can manipulate the managers' equilibrium strategies by setting the appropriate transfer prices. Plugging (33) into HQ $i$ 's first order condition (32) yields the transfer price equilibrium for the first stage game:

$$
t_{i 1}^{*}=\delta q_{i 2}^{*}\left(t_{i 2}^{*}\right)-\Delta_{i}\left(a_{j 1}\right) / \frac{\partial q_{i 1}^{*}}{\partial t_{i 1}}, \quad i, j \in\{1,2\}, i \neq j .
$$


Obviously, both firms' transfer prices are deviating from the marginal costs of the congested service which are given by the first term in (35). The direction of the deviation from marginal cost depends on the sign of the strategic component $\Delta_{i}\left(a_{j 1}\right)$. As stated in Lemma 4 , the sign of the strategic term is solely determined by the nature of competition:

Lemma 4 The strategic component $\Delta_{i}\left(a_{j 1}\right)$ is strictly positive under price competition and strictly negative under quantity competition:

$$
\Delta_{i}\left(p_{j 1}\right):=\frac{\partial \Pi_{i 1}}{\partial p_{j 1}} \frac{\partial p_{j 1}^{*}}{\partial t_{i 1}}>0, \quad \Delta_{i}\left(q_{j 1}\right):=\frac{\partial \Pi_{i 1}}{\partial q_{j 1}} \frac{\partial q_{j 1}^{*}}{\partial t_{i 1}}<0 .
$$

Proof see appendix

From Lemma 3 and Lemma 4 the strategic transfer pricing equilibrium can be characterized by the following proposition:

Proposition 2 Under price competition (quantity competition) both HQ's charge their duopolistic departments transfer prices above (below) the marginal cost of the congested service.

Proof Obvious from Lemma 3, Lemma 4 and (35).

To provide the intuition behind this result, consider first the example of a linear demand function duopoly under price competition as exhibited in Figure $1^{17}$. The starting point of the analysis is the NASH-equilibrium of the centralized firms at point $N$ which is determined by the intersection of the reaction functions $p_{11}\left(p_{21}\right)$ and $p_{21}\left(p_{11}\right)$. The corresponding equilibrium profits are denoted by $\Pi_{1}^{N}$ and $\Pi_{2}^{N}$. This equilibrium would obviously be achieved in the managers' subgame when both firms would charge their departments the marginal cost of the congested service. However, when both HQ's are charging transfer prices above marginal cost, the managers' reaction functions are shifted away from the origin arriving at the new equilibrium point $K$ where either manager's isoprofit curve has a tangency point with its competitor's reaction function. In the new equilibrium both firms are charging higher prices resulting in higher profit levels than in the original equilibrium at point $N$. Thus, the overall intensity of competition is lowered by strategic transfer pricing because both firm's managers act as softer competitors than their HQ's would do under centralized decision making. Furthermore, since the manager's equilibrium strategies would not be profit maximizing, and hence incredible for their HQ's, delegation strictly dominates centralization.

\footnotetext{
${ }^{17}$ See also Göx (1998) for a similar illustration for the case of strategic transfer pricing in presence of a competitive intermediate product market.
} 
Figure 1: Transfer pricing equilibrium under price competion

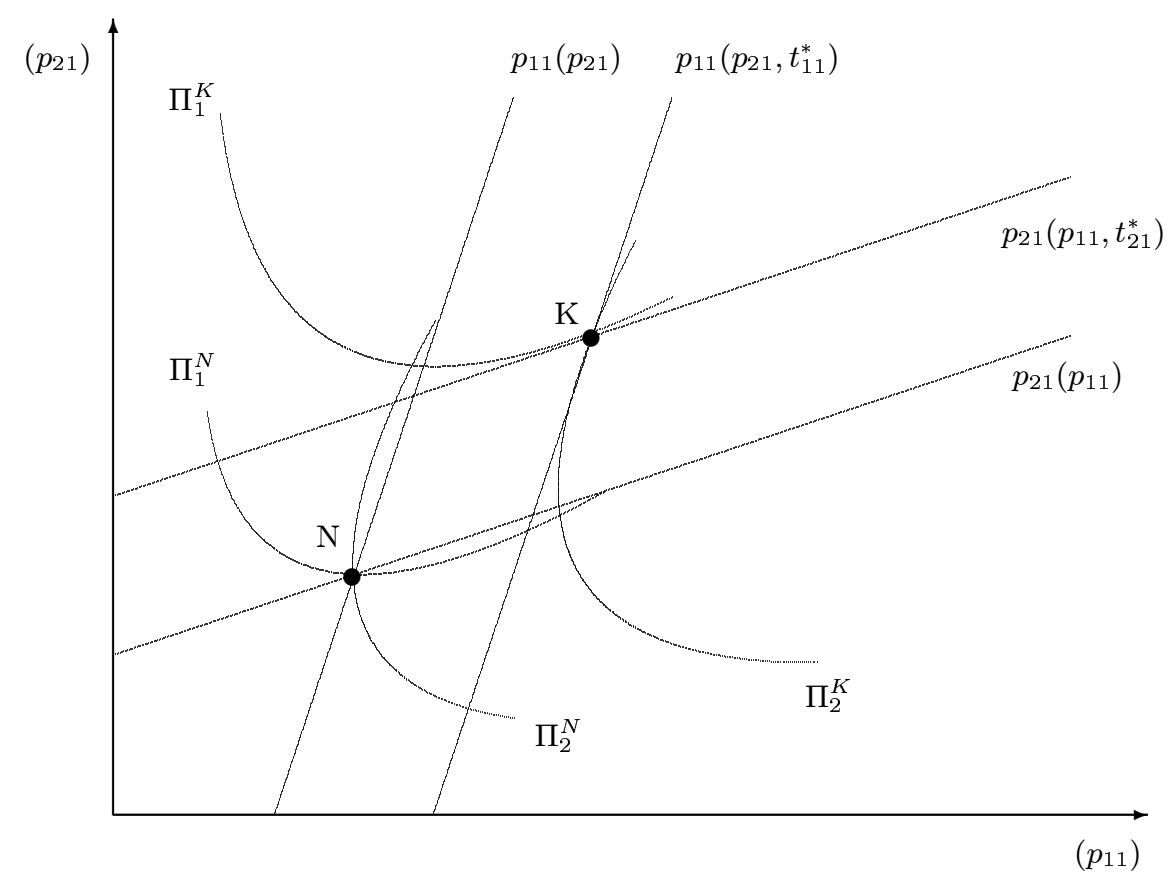

This rationale also holds under quantity competition although the equilibrium outcome is not beneficial for both firms as illustrated in Figure 2. Starting again from the equilibrium of the centralized firms at point $N$, the subsidized transfer prices will shift the manager's reaction functions away from the origin arriving at the new equilibrium point $G$. In the new equilibrium both managers are selling higher quantities on the final product market. Accordingly, the market price will fall and both firms will earn strictly lower profits than under centralized decision making. Thus, strategic transfer pricing under quantity competition increases the intensity of competition to the mutual disadvantage of both firms. However, if one of the firms would desist from delegating the authority over the product market decision to the manager or equivalently charge his manager only the marginal cost of the congested service, the consequences would be even more detrimental for the firm.

Consider, for example the case where firm 1 sets its transfer price strategically while firm 2 prefers a centralized output market strategy. Given these conditions, firm 1 could implement any product market equilibrium in the subgame between its managers and HQ 2 along the reaction curve $q_{21}\left(q_{11}\right)$ by subsidizing the transfer price for the congested service. In other words, changing the transfer price is equivalent to shifting the marketing 
Figure 2: Transfer pricing equilibrium under quantity competion

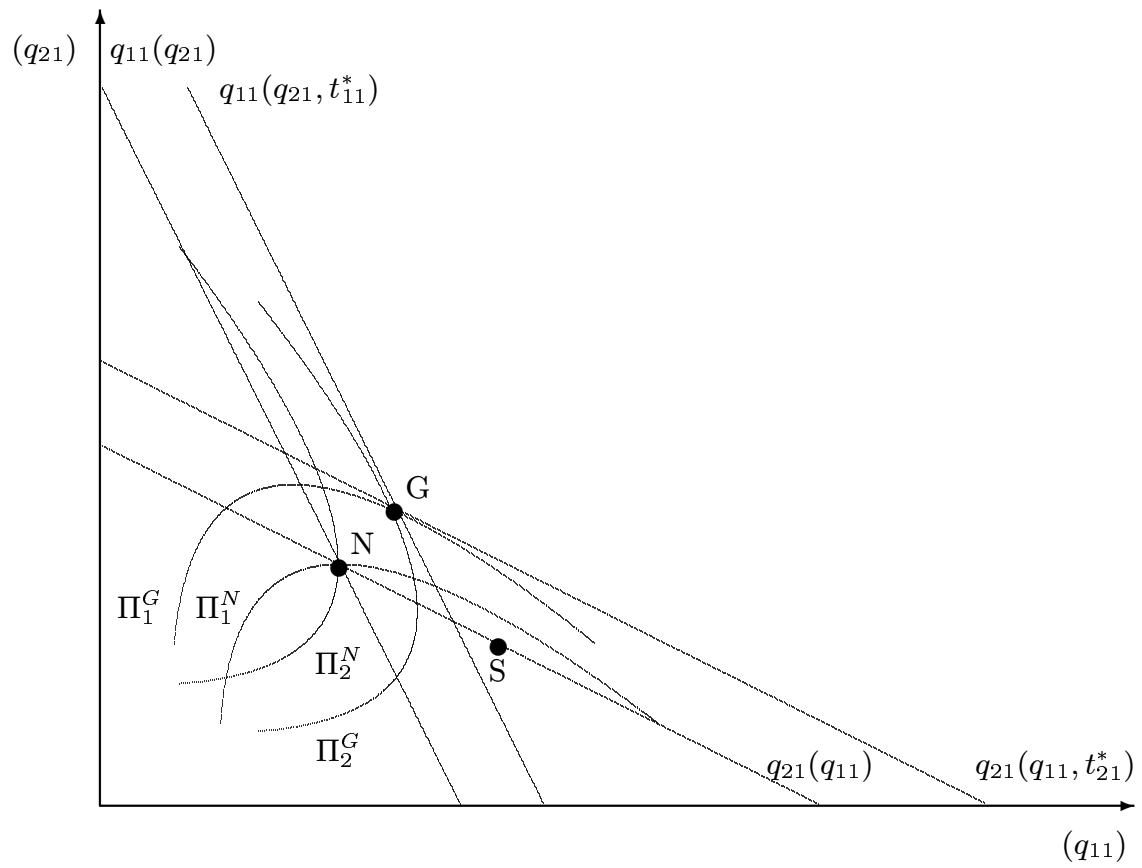

manager's reaction function to the desired intersection point with the (constant) reaction function of the centralized competitor. Obviously, firm 1 would prefer the equilibrium at point $S$ where its isoprofit curve has a tangency point with the reaction function of firm 2. Thus, firm 1 would become the STACKELBERG-leader while firm 2 would become the STACKELBERG-follower. It is easy to see from Figure 2 that firm 1 would earn a higher profit than in the symmetric transfer pricing equilibrium at point $G$, while firm 2's isoprofit curve would shift to the right representing a lower profit laver than at point $G$. Since both firms have a strict incentive to avoid the worst case of earning the profit of the STACKELBERG-follower, they strictly prefer to subsidize their transfer prices although both firms would be better off by charging only the marginal cost of the centralized service. Thus, the firms are facing a prisoners' dilemma because the inefficient subsidization policy is a dominant strategy equilibrium ${ }^{18}$.

\footnotetext{
${ }^{18}$ See also Hughes/KaO (1998) who obtain similar results for the quantity competion/cost allocation case by performing numerical computations.
} 


\subsection{Strategic Cost Allocation}

The final step of the analysis is to investigate the performance of a tidy cost allocation rule against strategic transfer pricing in the competitive environment. While in the literature the use of tidy cost allocations has only been analyzed for the case of quantity competition, the model of this section also considers the possibility that the firms compete in prices ${ }^{19}$. Like in section 3.3 it will be assumed, that both firms allocate the total cost of the congested service to their marketing departments. Let $\alpha_{i}, \alpha_{i} \in[0,1]$ denote the cost share of the duopolistic department 1 in firm $i$, then the remaining cost share of the monopolistic department 2 is given by $1-\alpha_{i}$. Accordingly the divisional profits of firm $i$ are given by

$$
\Pi_{i 1}\left(a_{i 1}, a_{j 1}, q_{i 2}\right)= \begin{cases}p_{i 1}\left(q_{i 1}, q_{j 1}\right) q_{i 1}-\alpha_{i} \delta q_{i 1} q_{i 2} & \text { for } \quad \mathbf{a}=\mathbf{q} \\ p_{i 1} q_{i 1}\left(p_{i 1}, p_{j 1}\right)-\alpha_{i} \delta q_{i 1}\left(p_{i 1}, p_{j 1}\right) q_{i 2} & \text { for } \quad \mathbf{a}=\mathbf{p}\end{cases}
$$

and

$$
\Pi_{i 2}\left(q_{i 1}, q_{i 2}\right)=R_{i 2}\left(q_{i 2}\right)-\left(1-\alpha_{i}\right) \delta q_{i 1} q_{i 2}, \quad i \in\{1,2\} .
$$

Since $\Pi_{i 1}$ is a function of $q_{i 2}$, the managers of the competing divisions must not only consider the market game in determining their strategies $a_{i 1}$ but also the internal production game between both divisions of the same firm. On the other hand, the managers of the monopolistic departments must anticipate the output market equilibrium to determine their optimal production strategies because $\Pi_{i 2}$ is a function of both $q_{i 2}$ and $q_{i 1}$. The second stage game structure is therefore more complex than in the strategic transfer pricing case or the cost allocation/multiproduct monopoly case respectively. However, to determine the optimal cost shares $\alpha_{1}$ and $\alpha_{2}$, we apply the well known to stage optimization procedure and first look for the equilibria of both the internal and the market game on stage two. Differentiating the profit functions (36) and (37) with respect to the managers' decisions $a_{i 1}$ and $q_{i 2}$ yields the first order conditions of firm $i$ 's division managers:

$$
\frac{\partial \Pi_{i 1}}{\partial a_{i 1}}=\left\{\begin{array}{c}
\frac{\partial p_{i 1}}{\partial q_{i 1}} q_{i 1}+p_{i 1}\left(q_{i 1}, q_{j 1}\right)-\alpha_{i} \delta q_{i 2}=0 \text { for } \mathbf{a}=\mathbf{q} \\
q_{i 1}\left(p_{i 1}, p_{j 1}\right)+\left(p_{i 1}-\alpha_{i} \delta q_{i 2}\right) \frac{\partial q_{i 1}}{\partial p_{i 1}}=0 \text { for } \mathbf{a}=\mathbf{p}
\end{array}\right.
$$

and

$$
\frac{\partial \Pi_{i 2}}{\partial q_{i 2}}=\frac{\partial R_{i 2}}{\partial q_{i 2}}-\left(1-\alpha_{i}\right) \delta q_{i 1}, \quad i \in\{1,2\} .
$$

Although closed form solutions can only be derived by solving the simultaneous equation system given by (38) and (39) for $a_{11}, a_{12}, q_{12}$, and $q_{22}$, the equilibrium strategies can

\footnotetext{
${ }^{19}$ In particular, Hughes/KAO (1998) consider the case of to multiproduct duopolies while GAL-OR (1993) considers a setting similar to this paper albeit the second division acts as a price taker on his market.
} 
still be expressed as functions of the cost allocation parameters $\alpha_{1}$ and $\alpha_{2}$ from HQ's perspective, yielding:

$$
a_{i 1}^{*}\left(\alpha_{i}, \alpha_{j}\right)=\underset{a_{i 1}}{\arg \max } \Pi_{i 1}\left(a_{i 1}, a_{j 1}^{*}, q_{i 2}^{*}, \alpha_{i}\right), \quad i, j \in\{1,2\}, i \neq j
$$

and

$$
q_{i 2}^{*}\left(\alpha_{i}, \alpha_{j}\right)=\underset{q_{i 2}}{\arg \max } \Pi_{k}\left(q_{i 1}^{*}, q_{i 2}, \alpha_{i}\right), \quad i, j \in\{1,2\}, i \neq j,
$$

where $q_{i 1}^{*}$ in (41) denotes the equilibrium demand $q_{i 1}^{*}\left(\alpha_{i}, \alpha_{j}\right):=q_{i 1}\left(p_{i 1}^{*}\left(\alpha_{i}, \alpha_{j}\right), p_{j 1}^{*}\left(\alpha_{i}, \alpha_{j}\right)\right)$ when the duopolists compete in prices. Following previous notation, the equilibrium profits are obtained by plugging the managers' equilibrium strategies into the profit functions (36) and (37):

$$
\begin{aligned}
\Pi_{i 1}\left(a_{i 1}^{*}\left(\alpha_{i}, \alpha_{j}\right), a_{j 1}^{*}\left(\alpha_{i}, \alpha_{j}\right), q_{i 2}^{*}\left(\alpha_{i}, \alpha_{j}\right), \alpha_{i}\right) & :=V_{i 1}\left(\alpha_{i}, \alpha_{j}\right), \\
\Pi_{i 1}\left(q_{i 1}^{*}\left(\alpha_{i}, \alpha_{j}\right), q_{i 2}^{*}\left(\alpha_{i}, \alpha_{j}\right), \alpha_{i}\right) & :=V_{i 2}\left(\alpha_{i}, \alpha_{j}\right) .
\end{aligned}
$$

Using these definitions and the fact that the total cost of the congested service is allocated to the divisions, the first stage optimization problem of HQ $i$ can be expressed as follows:

$$
\max _{\alpha_{i}} \Pi_{i}\left(\alpha_{i}, \alpha_{j}\right)=V_{i 1}\left(\alpha_{i}, \alpha_{j}\right)+V_{i 2}\left(\alpha_{i}, \alpha_{j}\right), \quad i, j \in\{1,2\}, i \neq j
$$

Unlike the multiproduct monopoly case the cost shares are determined as the equilibrium of a non-cooperative game between both firms' HQ's. The necessary conditions for an equilibrium of the first stage game are given by ${ }^{20}$

$$
\frac{d \Pi_{i}}{d \alpha_{i}}=\widehat{\Delta}_{i}\left(a_{j 1}\right)+\frac{\partial \Pi_{i 1}}{\partial q_{i 2}} \frac{\partial q_{i 2}^{*}}{\partial \alpha_{i}}+\frac{\partial \Pi_{i 2}}{\partial q_{i 1}} \frac{\partial q_{i 1}^{*}}{\partial \alpha_{i}}=0 \quad i, j \in\{1,2\}, i \neq j .
$$

where

$$
\frac{\partial \Pi_{i 1}}{\partial a_{j 1}} \frac{\partial a_{j 1}^{*}}{\partial \alpha_{i}}:=\widehat{\Delta}_{i}\left(a_{j 1}\right), \quad i, j \in\{1,2\}, i \neq j
$$

denotes the strategic impact of firm $i$ 's cost allocation choice on the equilibrium strategy of firm $j$ 's first division manager. Since raising $\alpha_{i}$ has the same effect as a transfer price increase in the last subsection's game, the managers' equilibrium reactions to a change of $\alpha_{i}$ are the same as stated for $q_{i 1}$ in Lemma 3. Thus, when firm 1 allocates more costs to department 1 , the division manager will raise its equilibrium price under price competition and reduce its equilibrium quantity under quantity competition. Accordingly, the manager of firm 2 will raise his equilibrium price as well in the former case and increase his equilibrium quantity in the latter case. However, since raising department 1 's cost means reducing the cost share of department 2, the manager of the monopolistic department in firm 1 will increase his output quantity in both cases. Thus, firm $i$ must

\footnotetext{
${ }^{20}$ See appendix for a derivation of the first order condition.
} 
not only consider the strategic effect like in the last subsection but also the impact on the internal production equilibrium like in section 3.3 in determining the optimal cost share $\alpha_{i}$. Utilizing

$$
\frac{\partial \Pi_{i 1}}{\partial q_{i 2}}=-\alpha \delta q_{i 1}^{*}\left(\alpha_{i}, \alpha_{j}\right), \text { and } \frac{\partial \Pi_{i 2}}{\partial q_{i 1}}=-(1-\alpha) \delta q_{i 2}^{*}\left(\alpha_{i}, \alpha_{j}\right), \quad i, j \in\{1,2\}, i \neq j,
$$

we obtain the equilibrium cost shares by solving (43) for $\alpha_{i}$ :

$$
\alpha_{i}^{*}=\frac{q_{i 2}^{*}\left(\alpha_{i}, \alpha_{j}\right) \frac{\partial q_{i 1}^{*}}{\partial \alpha_{i}}-\widehat{\Delta}_{i}\left(a_{j 1}\right) / \delta}{q_{i 2}^{*}\left(\alpha_{i}, \alpha_{j}\right) \frac{\partial q_{i 1}^{*}}{\partial \alpha_{i}}-q_{i 1}^{*}\left(\alpha_{i}, \alpha_{j}\right) \frac{\partial q_{i 2}^{*}}{\partial \alpha_{i}}}, \quad i, j \in\{1,2\}, i \neq j .
$$

Comparing (44) with the optimal cost share $\alpha^{*}$ from equation (19) in the multiproduct monopoly case reveals that $\alpha_{i}^{*}$ differs from $\alpha^{*}$ by the term $\widehat{\Delta}_{i}\left(a_{j 1}\right) / \delta$ due to the impact of competition on the final product market. Since $\alpha_{i}$ and the transfer price $t_{i 1}$ of the last subsection have the same directional effect on the profit of department $i 1$, and thus on the final product market equilibrium in duopoly, the sign of the strategic effect can be analogously determined from Lemma 3 and Lemma 4: From

$$
\frac{\partial \Pi_{i 1}}{\partial q_{j 1}}=\frac{\partial p_{i 1}}{\partial q_{j 1}} q_{i 1}<0, \quad \frac{\partial \Pi_{i 1}}{\partial p_{j 1}}=\left(p_{i 1}-\alpha_{i} \delta q_{i 2}\right) \frac{\partial q_{i 1}}{\partial p_{j 1}}>0, \quad i, j \in\{1,2\}, i \neq j
$$

and

$$
\frac{\partial q_{j 1}^{*}}{\partial \alpha_{i}}>0, \frac{\partial p_{j 1}^{*}}{\partial \alpha_{i}}>0, \quad i, j \in\{1,2\}, i \neq j
$$

according to Lemma 3 we obtain the following expressions:

$$
\widehat{\Delta}_{i}\left(q_{j 1}\right)=\frac{\partial \Pi_{i 1}}{\partial q_{j 1}} \frac{\partial q_{j 1}^{*}}{\partial \alpha_{i}}<0 \quad \text { and } \quad \widehat{\Delta}_{i}\left(p_{j 1}\right)=\frac{\partial \Pi_{i 1}}{\partial p_{j 1}} \frac{\partial p_{j 1}^{*}}{\partial \alpha_{i}}>0, \quad i, j \in\{1,2\}, i \neq j
$$

indicating that the strategic effect works in the same direction as in the strategic transfer pricing equilibrium. To sign the remaining terms in the optimal solution (44) the internal equilibrium between both departments of the same firm must also be considered. However, since the impact of a change in department 1's cost share on the production equilibrium in firm $i$ is given by

$$
\frac{\partial q_{i 1}^{*}}{\partial \alpha_{i}}<0 \quad \text { and } \quad \frac{\partial q_{i 2}^{*}}{\partial \alpha_{i}}>0, \quad i \in\{1,2\}
$$

from Lemma 2 , and $\partial q_{i 1}^{*} / \partial \alpha_{i}<0$ also holds for the impact of a change of $\alpha_{i}$ on the duopoly equilibrium from Lemma 3, we can conclude that both the denominator and the first term of the numerator of (44) are strictly negative for arbitrary interior solutions of the second stage subgames. It follows therefore from the sign of the strategic component, that both firms allocate less costs to department 1 than they would allocate for achieving internal efficiency under quantity competition, whereas under price competition both firms allocate 
a larger cost share to department 1 than required to attain internal efficiency. Given these observations and the boundaries on $\alpha_{i}$ we can identify three possible solutions

$$
\alpha_{i}^{*}=\left\{\begin{array}{ccc}
0 & \text { if } & q_{i 2}^{*}\left(\alpha_{i}, \alpha_{j}\right) \frac{\partial q_{i 1}^{*}}{\partial \alpha_{i}}-\widehat{\Delta}_{i}\left(q_{j 1}\right) / \delta \geq 0 \\
\in(0,1) & & \text { otherwise } \\
1 & \text { if } & \widehat{\Delta}_{i}\left(p_{j 1}\right) / \delta-q_{i 1}^{*}\left(\alpha_{i}, \alpha_{j}\right) \frac{\partial q_{i 2}^{*}}{\partial \alpha_{i}} \geq 0
\end{array}\right.
$$

The corner solutions in the first and third row of (47) refer to the cases where the strategic effect governs the cost allocation choice of both firms under quantity competition and price competition respectively. Where $\alpha_{i}^{*}=0$ is obtained when the denominator of (44) becomes positive under quantity competition which is very likely when department 2 is relatively unimportant in terms of its output quantity $q_{i 2}^{*}\left(\alpha_{i}, \alpha_{j}\right) . \alpha_{i}^{*}=1$ is the optimal allocation strategy when the numerator of (44) becomes larger than the denominator (in absolute values) which is only possible under price competition when the output of department 1 is relatively small. Finally, the interior solution $\alpha_{i}^{*}(0,1)$ where both departments bear a share of the service department's costs is obtained under both forms of competition when these conditions are not met. Regardless of the actual solution, the strategic rationale directs the firms ceteris paribus to subsidize their first department under quantity competition and to charge it a higher cost share under price competition than in the multiproduct monopoly case. The incentives for this behavior have been explained in the last section.

However, the central issue of the paper has not been resolved yet: Can a firm improve its profitability by using a tidy cost allocation rule in a competitive environment? Recall first from Proposition 1 that the tidyness requirement prevents the firm from achieving internal efficiency in the absence of competition. Recall next from Lemma 1 that transfer prices impose no restrictions on the admissible set of production policies that can be achieved by delegation. Thus, we can conclude that the cost shares resulting from the strategic transfer pricing equilibrium given by (35) are appropriate benchmarks for the firms' optimal cost shares when the tidyness requirement would be removed. From (35) and the fact that the unrestricted equilibrium cost share of department $i k$ is given by $t_{i k}^{*} q_{i k}^{*}$, we obtain the following benchmark solution for department 1 :

$$
\begin{aligned}
C_{i 1}^{*} & =t_{i 1}^{*} q_{i 1}^{*}\left(t_{i 1}^{*}, t_{j 1}^{*}\right)=\left(\delta q_{i 2}^{*}\left(t_{i 2}^{*}\right)-\Delta_{i}\left(a_{j 1}\right) / \frac{\partial q_{i 1}^{*}}{\partial t_{i 1}}\right) q_{i 1}^{*}\left(t_{i 1}^{*}, t_{j 1}^{*}\right) \\
& =C_{i 0}(\cdot)-\Delta_{i}\left(a_{j 1}\right) q_{i 1}^{*}\left(t_{i 1}^{*}, t_{j 1}^{*}\right) / \frac{\partial q_{i 1}^{*}}{\partial t_{i 1}}
\end{aligned}
$$

Thus, the optimal cost share for department 1 is given by the sum of the total cost of the service department and a second term capturing the strategic component. Since $\Delta_{i}\left(q_{j 1}\right)<0, \Delta_{i}\left(p_{j 1}\right)>0$, and $\partial q_{i 1}^{*} / \partial t_{i 1}<0$, we can conclude that the optimal cost share of division 1 should exceed the total cost of the congested service under price competition 
and that the optimal cost share under quantity competition should be less than the total cost of the congested service. Furthermore, the optimal cost share of division 2,

$$
C_{i 2}^{*}=t_{i 2}^{*} q_{i 2}^{*}\left(t_{i 2}^{*}\right)=\delta q_{i 1}^{*}\left(t_{i 1}^{*}, t_{j 1}^{*}\right) q_{i 2}^{*}\left(t_{i 2}^{*}\right)=C_{i 0}(\cdot)
$$

equals the total costs of the service department. This is exactly the cost share that replicates the centralized quantity decision for the monopoly department because delegation has no strategic impact in the absence of competition. Given these benchmark allocations for the unrestricted case, we can draw the following conclusion:

Proposition 3 There exists no tidy cost allocation scheme that improves the firms profitability under price competition, whereas a tidy cost allocation rule can eventually replicate the unrestricted (transfer pricing) solution under quantity competition.

Proof Both parts of the proof follow immediately from (47), (48) and (49)

price competition: $C_{i 1}^{*}>\alpha_{i}^{*} C_{i 0}$ and $C_{i 2}^{*}>\left(1-\alpha_{i}^{*}\right) C_{i 0} \quad \forall \quad \alpha_{i}^{*} \in(0,1]$ quantity competition: $C_{i 1}^{*}=\alpha_{i}^{*} C_{i 0}$ and $C_{i 2}^{*}=\left(1-\alpha_{i}^{*}\right) C_{i 0}$ if and only if $\alpha_{i}^{*}=C_{i 1}^{*}=0$

Thus, a strategic transfer pricing policy (weakly) dominates a tidy cost allocation rule not only in the light of internal efficiency like in the multiproduct monopoly case but also as a strategic device. Under price competition the tidyness requirement thwarts any strategic benefit for the divisionalized firm because only a cost share $\alpha_{i}^{*}>1$ would shift the equilibrium strategies in duopoly into the desired direction. Moreover, the monopoly department will always produce an inefficiently large output quantity because the cost share of division 2 always falls below the optimal one $\left(\alpha_{i}^{*}=1\right)$. Finally, we can conclude for the case of price competition that a centralized firm will always earn a higher profit than a decentralized firm that employs a tidy cost allocation rule because centralization is equivalent to allocating $C_{i k}^{*}=C_{i 0}$ to each department which at least guarantees internal efficiency, albeit no strategic benefits can be achieved.

Under quantity competition a tidy cost allocation rule can be optimal in case of the corner solution $\alpha_{i}^{*}=0$ if and only if incidentally the additional condition $C_{i 1}^{*}=0$ (or equivalently $\left.C_{i 0}(\cdot)=\Delta_{i}\left(a_{j 1}\right) q_{i 1}^{*}\left(t_{i 1}^{*}, t_{j 1}^{*}\right) /\left(\partial q_{i 1}^{*} / \partial t_{i 1}\right)\right)$ is satisfied. If the second condition is not met, the firm allocates the optimal cost share to division 2 but not to division 1 . The opposite result can be obtained when it happens to be that $C_{i 1}^{*}=\alpha_{i}^{*} C_{i 0}$ for $\alpha_{i}^{*} \in(0,1)$. However, in both cases the resulting allocation is suboptimal from either the internal efficiency or the strategic perspective. Nevertheless, under quantity competition a decentralized firm committing to a tidy cost allocation rule can still outperform a centralized 
one because the strategic effect works in the right direction, albeit the benchmark profit of the decentralized firm using transfer prices as a commitment device will in general not be attained.

\section{$5 \quad$ Summary and Discussion of Results}

The results of the preceding performance comparison of transfer pricing and tidy cost allocations can be summarized as follows: In the absence of competition, tidy cost allocations are creating inefficient allocations within the firm while transfer prices can always be adjusted to replicate the first best solution of the centralized firm. While the second result is not surprising because it merely restates the well known result of Hirshleifer (1956), the first result draws a parallel to the impossibility of solving the free rider problem in team production by a profit sharing scheme.

Under duopolistic competition, transfer prices are still the best method to treat the congestion problem but the solution depends on nature of competition on the final product market. When firms compete in prices, the strategic rationale requires to allocate more than the total cost of the congested service to the duopolistic departments. While transfer prices can still be adjusted accordingly, the tidyness requirement prevents the cost allocation scheme from providing the desired strategic incentives to the firms' managers. Under quantity competition, the strategic motive requires to allocate less than the cost of the service to the duopolistic departments. Thus, a tidy cost allocation scheme does not contradict the required direction of the strategic effect. However, the optimal allocation is at best found incidentally while the transfer prices can again always be adjusted in an optimal way.

However, one important qualification must be made to these results with respect to the observability of the commitment device in the case of competition. Although it may be a reasonable assumption that the competitors in a small industry are informed about their internal accounting numbers, one should also consider the case where the internal accounting information is not shared by the competitors. Despite the fact that most of the relevant literature on the strategic use of accounting rules does not discuss the observability issue at all ${ }^{21}$, it has recently been shown by Göx (1998) that transfer prices cannot serve as a commitment device when they are not common knowledge unless the deviation from marginal cost can be made credible to the competitor for other than strategic reasons ${ }^{22}$.

\footnotetext{
${ }^{21}$ See e.g. Alles/Datar (1998) or Gal-Or (1993).

${ }^{22}$ See also KATz (1991) and BAGwell (1995) for a general treatment of the observability problem in strategic delegation games.
} 
The reason for this result is the fact, that the first mover advantage of the firms' HQ's disappears when the outcome of the first stage transfer pricing game cannot be observed before the managers are playing the market game on behalf of their principals. Rather, the agents must base their output market strategies on rational conjectures about the transfer pricing rules of their competitors' HQ like in a simultaneous game. Thus, a two stage game with unobserved first stage actions is equivalent to a simultaneous game where all players derive their expectations about the other players' equilibrium strategies from anticipating their profit maximization problems. Since a transfer price deviating from marginal cost would not be a profit maximizing strategy for either HQ in a simultaneous game, the managers will conjecture that neither HQ deviates from the marginal cost of the congested service. Moreover, because both HQ's anticipate the agents rational conjectures, they will indeed transfer the service at marginal cost. Thus, the outcome of the strategic transfer pricing game is equivalent to the equilibrium of the centralized firms ${ }^{23}$.

In contrast, the accurate cost shares of a decentralized firm using a tidy cost allocation rule need not be observed by its competitor's manager to provide equilibrium incentives. Rather, it is sufficient that both firms know that their competitor commits to the tidyness restriction albeit he does not observe the actual cost shares of the departments ${ }^{24}$. The reasoning behind this result is that the tidyness requirement acts as a binding self commitment for the firms' HQ's. Knowing that a firm commits to a tidy cost allocation rule is equivalent to knowing that each of the firm's departments will bear less than the total cost of the service department. Thus, the firm necessarily deviates from the optimal policy of a centralized firm which would be equivalent to allocating the total cost of the service department once to each user.

Given the desired directions of the strategic effects under both forms of competition, a tidy cost allocation rule can only outperform transfer prices under quantity competition, although one should keep in mind that both firms are still ending up with the prisoners' dilemma situation described in section 4.2. Thus, when a firm cannot commit to make its subsidized transfer price observable, it should decentralize and employ a tidy cost allocation rule for strategic purposes because otherwise it had to play the less attractive role of the STACKELBERG-follower on the duopoly market. Under price competition, however, unobservable transfer prices based on marginal cost allow both decentralized firms to attain the equilibrium profit of a centralized firm which has been shown to exceed the attainable profit under any tidy cost allocation rule. Accordingly, transfer pricing dominates tidy cost allocations under price competition regardless of the observability issue

\footnotetext{
${ }^{23}$ See Göx (1998) for a formal proof.

${ }^{24}$ See Hughes AND KaO (1998).
} 
although decentralization does no longer dominate centralization when transfer prices are not observable.

\section{Appendix}

Derivation of equation (17)

To solve the maximization problem

$$
\max _{\alpha} \Pi(\alpha)=V_{1}(\alpha)+V_{2}(\alpha)
$$

we first differentiate the equilibrium profit of division $k, V_{k}(\alpha)$, with respect to the cost share $\alpha$ :

$$
\frac{d V_{k}}{d \alpha}=\frac{\partial \Pi_{k}}{\partial q_{k}} \frac{d q_{k}^{*}}{d \alpha}+\frac{\partial \Pi_{k}}{\partial q_{l}} \frac{d q_{l}^{*}}{d \alpha}+\frac{\partial \Pi_{k}}{\partial \alpha} \quad k, l \in\{1,2\}, k \neq l .
$$

Since the first term must be zero from the equilibrium conditions (13) and (14) of the managers' subgame and the third term equals

$$
\frac{\partial \Pi_{1}}{\partial \alpha}=-\frac{\partial \Pi_{2}}{\partial \alpha}=-C_{0}
$$

we obtain the desired expression (17)

$$
\frac{\partial \Pi(\alpha)}{\partial \alpha}=\frac{\partial \Pi_{1}}{\partial q_{2}} \frac{d q_{2}^{*}}{d \alpha}+\frac{\partial \Pi_{2}}{\partial q_{1}} \frac{d q_{1}^{*}}{d \alpha}=0
$$

\section{Proof of Lemma 2}

To proof the claim that a marginal change of $\alpha$ leads to the following equilibrium reactions

$$
\frac{d q_{1}^{*}}{d \alpha}<0 \text { and } \frac{d q_{2}^{*}}{d \alpha}>0
$$

we first totally differentiate the system of implicit reaction functions of the division managers' subgame

$$
\frac{\partial \Pi_{k}\left(q_{k}, q_{l}, \alpha\right)}{\partial q_{k}}=0, \quad k, l \in\{1,2\}, k \neq l
$$

yielding

$$
\begin{aligned}
& \frac{\partial^{2} \Pi_{1}}{\partial q_{1}^{2}} d q_{1}+\frac{\partial^{2} \Pi_{1}}{\partial q_{1} \partial q_{2}} d q_{2}+\frac{\partial^{2} \Pi_{1}}{\partial q_{1} \partial \alpha} d \alpha=0 \\
& \frac{\partial^{2} \Pi_{2}}{\partial q_{2}^{2}} d q_{2}+\frac{\partial^{2} \Pi_{2}}{\partial q_{2} \partial q_{1}} d q_{1}+\frac{\partial^{2} \Pi_{2}}{\partial q_{2} \partial \alpha} d \alpha=0 .
\end{aligned}
$$


The solution of this equation system is given by

$$
\left[\begin{array}{c}
d q_{1} \\
d q_{2}
\end{array}\right]=\frac{1}{k}\left[\begin{array}{cc}
-\frac{\partial^{2} \Pi_{1}}{\partial q_{1}^{2}} & \frac{\partial^{2} \Pi_{2}}{\partial q_{2} \partial q_{1}} \\
\frac{\partial^{2} \Pi_{1}}{\partial q_{1} \partial q_{2}} & -\frac{\partial^{2} \Pi_{2}}{\partial q_{2}^{2}}
\end{array}\right]\left[\begin{array}{c}
\frac{\partial^{2} \Pi_{1}}{\partial q_{1} \partial \alpha} d \alpha \\
\frac{\partial^{2} \Pi_{2}}{\partial q_{2} \partial \alpha} d \alpha
\end{array}\right]
$$

where

$$
k=\frac{\partial^{2} \Pi_{1}}{\partial q_{1}^{2}} \frac{\partial^{2} \Pi_{2}}{\partial q_{2}^{2}}-\frac{\partial^{2} \Pi_{2}}{\partial q_{2} \partial q_{1}} \frac{\partial^{2} \Pi_{1}}{\partial q_{1} \partial q_{2}}>0
$$

must be positive by assumption to guarantee a unique equilibrium. Since

$$
\frac{\partial^{2} \Pi_{1}}{\partial q_{1} \partial \alpha}=-\delta q_{2}<0, \quad \frac{\partial^{2} \Pi_{2}}{\partial q_{2} \partial \alpha}=\delta q_{1}>0
$$

and

$$
\frac{\partial^{2} \Pi_{2}}{\partial q_{2} \partial q_{1}}=-(1-\alpha) \delta<0, \quad \frac{\partial^{2} \Pi_{2}}{\partial q_{1} \partial q_{2}}=-\alpha \delta<0
$$

we obtain the desired expressions by substituting into (51):

$$
\begin{aligned}
& \frac{d q_{1}}{d \alpha}=\frac{1}{k}\left(\frac{\partial^{2} \Pi_{2}}{\partial q_{2} \partial q_{1}} \frac{\partial^{2} \Pi_{2}}{\partial q_{2} \partial \alpha}-\frac{\partial^{2} \Pi_{1}}{\partial q_{1}^{2}} \frac{\partial^{2} \Pi_{1}}{\partial q_{1} \partial \alpha}\right)<0 \\
& \frac{d q_{2}}{d \alpha}=\frac{1}{k}\left(\frac{\partial^{2} \Pi_{1}}{\partial q_{1} \partial q_{2}} \frac{\partial^{2} \Pi_{1}}{\partial q_{1} \partial \alpha}-\frac{\partial^{2} \Pi_{2}}{\partial q_{2}^{2}} \frac{\partial^{2} \Pi_{2}}{\partial q_{2} \partial \alpha}\right)>0
\end{aligned}
$$

\section{Proof of Lemma 3}

The proof is similar to the proof of Lemma 2.Totally differentiating the system of the division managers's implicit reaction functions

$$
\frac{\partial \Pi_{i 1}\left(a_{i 1}, a_{j 1}, t_{i 1}\right)}{\partial a_{i 1}}=0, \quad i, j \in\{1,2\}, i \neq j
$$

yields

$$
\frac{\partial^{2} \Pi_{i 1}}{\partial a_{i 1}^{2}} d a_{i 1}+\frac{\partial^{2} \Pi_{i 1}}{\partial a_{i 1} \partial a_{j 1}} d a_{j 1}+\frac{\partial^{2} \Pi_{i 1}}{\partial a_{1} \partial t_{i 1}} d t_{i 1}=0, \quad i, j \in\{1,2\}, i \neq j
$$

By symmetry the solution of this equation system for $d a_{i 1}$ is given by

$$
d a_{i 1}=\frac{1}{k}\left(\frac{\partial^{2} \Pi_{j 1}}{\partial a_{j 1} \partial a_{i 1}} \frac{\partial^{2} \Pi_{j 1}}{\partial a_{j 1} \partial t_{j 1}} d t_{j 1}-\frac{\partial^{2} \Pi_{i 1}}{\partial a_{i 1}^{2}} \frac{\partial^{2} \Pi_{i 1}}{\partial a_{i 1} \partial t_{i 1}} d t_{i 1}\right), \quad i, j \in\{1,2\}, i \neq j
$$

where

$$
k=\frac{\partial^{2} \Pi_{11}}{\partial a_{11}^{2}} \frac{\partial^{2} \Pi_{21}}{\partial a_{21}^{2}}-\frac{\partial^{2} \Pi_{21}}{\partial a_{21} \partial a_{11}} \frac{\partial^{2} \Pi_{11}}{\partial a_{11} \partial a_{21}}>0
$$

from (25). Looking for the marginal equilibrium reactions on firm $i$ 's transfer price, we first obtain the following expressions by symmetry

$$
\left.\frac{d a_{i 1}}{d t_{i 1}}\right|_{d t_{j 1}=0}=\frac{\partial a_{i 1}^{*}\left(t_{i 1}, t_{j 1}\right)}{\partial d t_{i 1}}=-\frac{1}{k}\left(\frac{\partial^{2} \Pi_{i 1}}{\partial a_{i 1}^{2}} \frac{\partial^{2} \Pi_{i 1}}{\partial a_{i 1} \partial t_{i 1}}\right)
$$


and

$$
\left.\frac{d a_{j 1}}{d t_{i 1}}\right|_{d t_{j 1}=0}=\frac{\partial a_{j 1}^{*}\left(t_{j 1}, t_{i 1}\right)}{\partial t_{j 1}}=\frac{1}{k}\left(\frac{\partial^{2} \Pi_{i 1}}{\partial a_{i 1} \partial a_{j 1}} \frac{\partial^{2} \Pi_{i 1}}{\partial a_{i 1} \partial t_{i 1}}\right) .
$$

Utilizing the facts that the profit functions are assumed to be strictly concave and that by assumption

$$
\frac{\partial^{2} \Pi_{i 1}}{\partial q_{i 1} \partial q_{j 1}}<0, \quad \text { and } \quad \frac{\partial^{2} \Pi_{i 1}}{\partial p_{i 1} \partial p_{j 1}}>0
$$

and computing the mixed partial derivatives

$$
\frac{\partial^{2} \Pi_{i 1}}{\partial q_{i 1} \partial t_{i 1}}=-1<0, \quad \text { and } \quad \frac{\partial^{2} \Pi_{i 1}}{\partial p_{i 1} \partial t_{i 1}}=-\frac{\partial q_{i 1}}{\partial p_{i 1}}>0,
$$

we obtain the desired directions of the managers' equilibrium reactions

$$
\frac{\partial p_{i 1}^{*}}{\partial t_{i 1}}>0, \quad \frac{\partial p_{j 1}^{*}}{\partial t_{i 1}}>0, \quad \frac{\partial q_{i 1}^{*}}{\partial t_{i 1}}<0, \quad \frac{\partial q_{j 1}^{*}}{\partial t_{i 1}}>0
$$

Proof of Lemma 4

To proof that

$$
\Delta_{i}\left(p_{j 1}\right):=\frac{\partial \Pi_{i 1}}{\partial p_{j 1}} \frac{\partial p_{j 1}^{*}}{\partial t_{i 1}}>0, \quad \Delta_{i}\left(q_{j 1}\right):=\frac{\partial \Pi_{i 1}}{\partial q_{j 1}} \frac{\partial q_{j 1}^{*}}{\partial t_{i 1}}<0
$$

we first compute and sign the cross partial derivatives

$$
\frac{\partial \Pi_{i 1}}{\partial p_{j 1}}=\left(p_{i 1}-\delta q_{i 2}\right) \frac{\partial q_{i 1}}{\partial p_{j 1}}>0
$$

and

$$
\frac{\partial \Pi_{i 1}}{\partial q_{j 1}}=q_{i 1} \frac{\partial p_{i 1}}{\partial q_{j 1}}<0
$$

Since from Lemma 3

$$
\frac{\partial p_{j 1}^{*}}{\partial t_{i 1}}>0 \text { and } \quad \frac{\partial q_{j 1}^{*}}{\partial t_{i 1}}>0
$$

we obtain the desired result

Derivation of equation (43)

The first order condition for firm i's profit maximization problem

$$
\max _{\alpha_{i}} \Pi_{i}\left(\alpha_{i}, \alpha_{j}\right)=V_{i 1}\left(\alpha_{i}, \alpha_{j}\right)+V_{i 2}\left(\alpha_{i}, \alpha_{j}\right), \quad i, j \in\{1,2\}, i \neq j .
$$

is given by

$$
\frac{d \Pi_{i}}{d \alpha_{i}}=\frac{\partial V_{i 1}}{\partial \alpha_{i}}+\frac{\partial V_{i 2}}{\partial \alpha_{i}}=0 \quad \text { für } \quad i \in\{1,2\}
$$


Thus, we have to determine the partial derivatives of both divisions' value functions with respect to $\alpha_{i}$, yielding

$$
\frac{\partial V_{i 2}}{\partial \alpha_{i}}=\frac{\partial \Pi_{i 2}}{\partial q_{i 2}} \frac{\partial q_{i 2}^{*}}{\partial \alpha_{i}}+\frac{\partial \Pi_{i 2}}{\partial q_{i 1}} \frac{\partial q_{i 1}^{*}}{\partial \alpha_{i}}+\frac{\partial \Pi_{i 2}}{\partial \alpha_{i}}, \quad i \in\{1,2\},
$$

and

$$
\frac{\partial V_{i 1}}{\partial \alpha_{i}}=\frac{\partial \Pi_{i 1}}{\partial a_{i 1}} \frac{\partial a_{i 1}^{*}}{\partial \alpha_{i}}+\frac{\partial \Pi_{i 1}}{\partial a_{j 1}} \frac{\partial a_{j 1}^{*}}{\partial \alpha_{i}}+\frac{\partial \Pi_{i 1}}{\partial q_{i 2}} \frac{\partial q_{i 2}^{*}}{\partial \alpha_{i}}+\frac{\partial \Pi_{i 1}}{\partial \alpha_{i}}, \quad i, j \in\{1,2\}, i \neq j
$$

Using (50), the fact that the managers' first order conditions must hold in equilibrium and applying the definition of the strategic component

$$
\frac{\partial \Pi_{i 1}}{\partial a_{j 1}} \frac{\partial a_{j 1}^{*}}{\partial \alpha_{i}}:=\widehat{\Delta}_{i}\left(a_{j 1}\right), \quad i, j \in\{1,2\}, i \neq j
$$

we obtain

$$
\frac{d \Pi_{i}}{d \alpha_{i}}=\widehat{\Delta}_{i}\left(a_{j 1}\right)+\frac{\partial \Pi_{i 1}}{\partial q_{i 2}} \frac{\partial q_{i 2}^{*}}{\partial \alpha_{i}}+\frac{\partial \Pi_{i 2}}{\partial q_{i 1}} \frac{\partial q_{i 1}^{*}}{\partial \alpha_{i}}=0 \quad i, j \in\{1,2\}, i \neq j
$$

\section{References}

Alchian, Armen A./Demsetz, Harold (1972): Production, Information Costs, and Economic Organization, American Economic Review, Vol. LXII, p. 777-795.

Alles, Michael/Datar, Srikant (1998): Strategic Transfer Pricing, Management Science, Vol. 44., No. 4, p. 451-461.

Amershi, Amin H./Cheng, Peter (1990): Intrafirm Resource Allocation: The Economics of Transfer Pricing and Cost Allocations in Accounting, Contemporary Accounting Research, Vol. 7, p. 61-99.

Bagwell, Kyle (1995): Commitment and Observability in Games, Games and Economic Behavior, Vol. 8, p. 271-280.

Banker, Rajiv D./Datar, Srikant M. (1992): Optimal Transfer Pricing under Postcontract Information, Contemporary Accounting Research, Vol. 8, No. 2, p. 329352 .

Brander, J. A. And B. J. Spencer (1983). Strategic Commitment with R\&D: The Symmetric Case, Bell Journal of Economics, Vol. 14, p. 225-235.

Bulow, Jeremy I./Geanakoplos, John D./Klemperer, Paul D. (1985): Multimarket Oligopoly: Strategic Substitutes and Complements, Journal of Political Economy, Vol. 93, No. 3, p. 488-511. 
Christensen, John,/Demski Joel F. (1989): Transfer Pricing in a limited communication setting, working paper, Odense and Yale University.

Demski, Joel S. (1981): Cost Allocation Games, in: Moriarity, Shane (Ed.): Joint Cost Allocations, S. 142-173, Norman.

Dixit, Avinash (1986): Comparative Statics for Oligopoly, International Economic Review, Vol. 27, No. 1, p. 107-122.

Edlin, Aaron S./Reichelstein, Stefan (1995): Specific Investment under Negotiated Transfer Pricing: An Efficiency Result, Accounting Review, Vol. 70, No. 2, p. 275-291.

Fershtman, Chaim/Judd, Kenneth L. (1987): Equilibrium Incentives in Oligopoly, The American Economic Review, Vol. 77, No. 5, p. 927-940.

Göx, Robert F. (1998): Strategic Transfer Pricing, absorption costing and vertical integration, working paper, University of Magdeburg.

GaL-Or, Esther (1993): Strategic Cost Allocation, The Journal of Industrial Economics, Vol. 39, No. 4, p. 387-402.

Hirshleifer, JACK (1956): On the Economics of Transfer Pricing, Journal of Business, p. $172-184$.

Holmström, Bengt (1982): Moral Hazard in Teams, Bell Journal of Economics, Vol. 13, No. 2, p. 324-340.

Hughes, John S./Kao, Jennifer L. (1998): Cross Subsidization, Cost Allocation, and Tacit Coordination, Review of Accounting Studies, Vol. 2, p. 265-293.

Narayanan, V. G./Smith, Michael (1998): Impact of Competition and Taxes on Responsibility Center Organization and Transfer Prices, working paper, Harvard University and Duke University.

Jaqemin, Alexis/ Slade Margaret, E. (1989), Cartels, Collusion and Horizontal Merger, in: Schmalensee, Richard/Willig, Robert D. (Eds.), Handbook of Industrial Organization, Vol. I, p. 415-473.

Katz, Michael L. (1991): Game-playing Agents: Unobservable Contracts as Precommitments, Rand Journal of Economics, Vol. 22, No. 3, p. 201-228.

Ronen, Joshua/Balachandran, Kashi R. (1988): An Approach to Transfer Pricing Under Uncertainty, Journal of Accounting Research, Vol. 26, No. 2, p. 300-314. 
Schelling, Thomas C. (1960): The Strategy of Conflict, Cambridge.

Sklivas, Steven D. (1987): The Strategic Choice of Managerial Incentives, Rand Journal of Economics, Vol. 18, No. 3, p. 452-458.

Tirole, Jean (1988): The Theory of Industrial Organization, Cambridge/London.

Vaysman, Igor (1996): A Model of Cost-based Transfer Pricing, Review of Accounting Studies, Vol. 1, No. 1, p. 73-108.

Vickers, John (1985): Delegation and the Theory of the Firm, Economic Journal, Vol. 95, p. $138-147$.

Wagenhofer, Alfred (1994): Transfer Pricing under Asymmetric Information - An Evaluation of Alternative Methods, European Accounting Review, Vol. 1, p. 71-104.

Zimmerman, Jerold L. (1979): The Cost and Benefits of Cost Allocations, Accounting Review, Vol. 54, No. 3, p. 122-139. 